it up, for during the past year I have personally sent out over 20,000 copies of the "Great American Fraud," besides tens of thousands of my own leaflets on that subject. Physicians who understand my work are much interested in it, and many have helped me. May I not hope that a great avalanche of postal cards or letters will reach me in response to this appeal? Will it be fair for me to assume that, if only a few answer, only a few are interested in the questions to be discussed at the Congress on Alcoholism?

(Mrs.) Martha M. Alien, Marcellus, N. Y.

\section{Eye Bandage and Priority of Description}

To the Editor:-In reply to Dr. Friedenwald's letter in THE Journal, April 10, page 1196, I wish to state that I have used the eye bandage for ten years, and have failed to find it described or illustrated in the text-books or journals at my disposal. For that reason I published the article. I would not knowingly claim anything belonging to another.

G. A. Mortey, Crookston, Minn.

\section{Queries and Minor Notes}

Axoxymous Commusications will not be noticed. Queries for this column must be accompanied by the writer's name and address, but the request of the writer not to publish name or address will be faithfully observed.

\section{WORMS IN EGGS}

To the Editor:-Some time ago one of my patients opened a hen's egg, in the white of which was a small worm about onetwelfth of an inch thick and one and one-half inches long. The egg and the worm were given to me, but were accidentally destroyed. In the Medical World, February, 1909, page 62, I find recorded a similar observation. Can you give me any further in. formation on this subject?

Weslex C. Stick, Hanover, Pa.

AxSWER.-It occasionally happens that intestinal parasites wander from the intestines into the female genital ducts. This is a particularly easy matter in the case of birds, where the intestine and oviduct discharge into $a^{*}$ common genitointestinal cloaca. From the brief description of the parasite it is probable that it was a nematode, possibly the Heterakis perspicillum (Rudolphi, 1803). This worm lives in the small intestine of fowls, and on wandering into the oviduct may becone surrounded by albumin during the formation of the egg, but before the formation of the eggshell. It has been observed in the egg on a number of occasions. The worm has never been reported as a parasite of man and its size would. generally, lead to its discovery before being swallowed. It has, therefore, no practical medical importance.

occaslonally a rather closely allied parasite of man, the common pln worm (Oxyuris vermicularis) wanders from the rectum through the anus, and after entering the vagina, makes its way further up the genital tract. Occasionally, too, certain trematodes belonging to the genus Prosthogonimus (as $P$. ovatus) are found in the hen's egg. Such cases have been reported by Diesing in 1850 , Iandois in 1882 , Linton in 1887 , Spencer in 1889 and Ralllet in 1893. These parasites inhabit the bursa fabricii whence they enter the oviduct and are easily included in the albumin before the eggshell is formed.

\section{THE BLACK MOTOR CAR IN THE AU'TOMOBILE NUMBER}

The Jourxal has issued three Automobile Numbers, in 1906 , 1908 and 1909 . The contributions from physicians published therein have been accepted from the authors as fair and unprejudiced testimonies and very little complaint of any unfairness has come to The Journal. In the third number, however, March 6, 1909, there was only one contribution referring to the cars made by the Black Manufacturing Company, of $124 \mathrm{E}$. Ohio St., Chicago. The author of that letter had had unfortunate experience with his car, and his letter was a most unfavorable criticism. The publication of this letter caused a great many protests to be sent to THE Jourvar from satisfled owners of Black automobiles. Instead of selecting any one of these letter's for publication, we will merely say that they are from physicians in various parts of the country who have tested the Black automobile in country practice, over all kinds of roads, including sand and mud. These writers speak as favorably of their cars as do those who use other medium-priced cars. It seems evident, therefore. that it is unfair to judge the products of this company by the testimony of one man whose experience had been unsatisfactory.
MOLIS, CASTS AND MODFLS

To the Editor:-THE JoURNal has made me disgruntled by allowing contributors to speak of all kinds of splints, molds and molded splints indiscriminately as "casts." The iron-worker knows the difference between a mold and $a$ cast, and the artist distinguishes between his models, molds and casts. It is rather irritating, therebetween his models, molds and casts. It is rather irritating, thererere, to find our medical brothers less particular. A recent articlo l'eached the point of absurdity. Five times the word "cast" was a plaster-of-Paris reproduction, of a leg was called, not a "cast," a plaster-of-Paris reproduction, of a leg was called, not a "cast," tended for reproduction; instead, an appliance was to be fitted on it. In this case the human leg was the "model" and the cast reproduced it. The cast was not to be used as a model for anything. The editors of THE JoURnal have taken many liberties with my articles. They have changed anything that seemed good to them, even to the title, and the articles have always gained in clearness thereby. And I can not believe that THE JOURNAL's contributors would feel hurt if the editol's were to rescue them from a misus
of ordinary English words.

ANSwER.-Our colrespondent is undoubtedly right in the distinc. tion which he draws between a mold-a form or matrix for shaping something in a fluid or plastic condition-and a cast-a reverse copy, in some plastic material, of a mold. We fail to find, however, that he is fully justified in his contention in regard to the word "model." According to the Standard Dictionary, a model is "an object, usually in miniature, representing accurately something to be made or already existing . . . A model may be either the thing to be copled or the copy that has been made from it." Thus, a miniature reproduction of a ship is called a "model," though not intended to serve as a pattern in making future ships.

\section{TO DISGUISE THE ODOR OF ETHER}

To the Editor:- What will effectively disguise the pungent odor of ether? I do not want an oil, but would like some alcoholic or ethereal extract like cologne, etc., that would accomplish the purpose. D. KRAMER, New York.

Answer.-Compound esters like ethyl acetate (acetic ether) or amyl acetate, or valerianate might be tried, but some of the essential oils such as oil of wintergreen, sassafras, etc., would be more efficient.

\section{The Public Service}

\section{Army Changes}

Memorandum of changes of stations and duties of medical officers for the week ended April 24, 1909:

Hartnett, E. H., major, ordered to duty at Fort Du Pont, Lel., on the expiration of his present leave of absence.

Murray, A., capt., ordered to Fort Du Pont, Del., instead of the hilippines division.

'Teff, W. H., capt., Fort Baker, Cal., ordered to duty with troops at Sequoia National Fark, Cal.

Cox, W., capt., honorably, discharged from the service of the Lnited States, with one year's pay.

Richards, $R$. L., capt., relieved from duty at Fort Wayne, Mich., and ordered to Washington, $D$. C., for a special course of instruction at the Army Medical School.

Yost, J. D., capt., granted leave of absence for one month.

Coffin, J. M., capt., relieved from duty at the Army and Navy General Hospital, Hot Springs, Ark.; will sail July $\overline{5}, 1009$, for Philippine service.

Snyder, H. D., Smith, A. M., Wilson, J. S., Fuller, L. A., Skinduty in the Philippines division in time to sail July 15 for San Francisco.

Reynolds, C. R., capt., relleved from duty with Company C, IIospital Corps, and ordered to duty at the Walter Reed Army General Hospital, Washington, D. C.

Woodruff, C. E., major, Kirkpatrick, T. J., major, relieved from duty at Fort Wadsworth, N. Y., and Fort iroultrie, S. C., respectively, in time to proceed to San Francisco and sail July 5,1909 , Hess, L. T., major, granted an extension of one month to his leave of absence.

Perley, H. O., colonel, ordered at the expiration of his present leave of absence to Denver, for duty as chief surgeon, Department of the Colorado, and attending surgeon in Denver.

La Garde, L. A., lieut-col., when relieved from duty at Denver. ordered to San Francisco for duty as chief surgeon, Department of California.

Kean, J. R., lieut-col., ordered to New York City, to represent the medical department of the army at the meeting of the Nedical Society of the County of New York, April $26,1909$.

Graves, L. K. M. R. C., honorably discharged from the service of the United States May 8, 1909, his services being no longer required; granted leave of absence to include May 8 .

Kierulff, H. N., M. R. C., granted leave of absence for 23 days. Johnson, T. II., M. R. C., ordered to active duty and assigned to duty at Fort Du Font, Del.

Foster, G. B., M. R. C., ordered to active duty, and assigned to uty at Fort Totten, $\mathrm{Y}$.

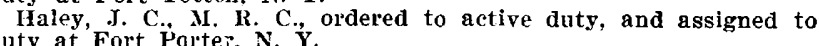
uty at Fort Parter, N. Y. Fox, J. S., M. R. C., ordered to active duty, and assigned to duty
at Fort Sam Hcustion, Texas. 